\title{
Giant Hepatomegaly with Spleno-testicular Enlargement in a Patient with Apolipoprotein A-I Amyloidosis: An Uncommon Type of Amyloidosis in Japan
}

\author{
Tsuneaki Yoshinaga ${ }^{1,2}$, Nagaaki Katoh ${ }^{1}$, Masahide Yazaki ${ }^{2,3}$, Mitsuto Sato ${ }^{1}$, Fuyuki Kametani ${ }^{4}$, \\ Hideo Yasuda ${ }^{5}$, Kyohei Watanabe ${ }^{6}$, Kazuhito Kawata ${ }^{7}$, \\ Mayuko Nakagawa ${ }^{2,3}$ and Yoshiki Sekijima ${ }^{1,2}$
}

\begin{abstract}
:
Hereditary systemic amyloidosis aside from transthyretin-related familial amyloid polyneuropathy is quite uncommon in Japan. We herein report a sporadic case of hereditary apolipoprotein A-I (apoAI) amyloidosis. The patient was a 43-year-old Japanese man who exhibited marked hepatomegaly with spleno-testicular enlargement. While he was initially thought to have primary AL amyloidosis, a proteomics analysis revealed that the amyloid was composed of variant apoAI with an E34K variant. To date, only one patient with apoAI amyloidosis has been reported in Japan. However, our study suggests that more patients may be present in Japan, and the majority may have been diagnosed with other types of amyloidosis due to its clinical similarity.
\end{abstract}

Key words: hereditary systemic amyloidosis, ApoAI amyloidosis, hepatic amyloidosis, testicular amyloidosis, proteomic analysis

(Intern Med 60: 575-581, 2021)

(DOI: 10.2169/internalmedicine.5126-20)

\section{Introduction}

Over 30 distinctive precursors of amyloid fibrils have been identified as causes of different types of amyloidosis (1). Apolipoprotein A-I (apoAI) is a $28-\mathrm{kD}$ nonglycosylated protein mainly produced by the liver and intestine (2) that constitutes the major apolipoprotein of highdensity lipoprotein (HDL) and regulates its metabolism. In a mutated form, apoAI represents an amyloidogenic precursor in some cases of hereditary systemic amyloidosis (2), and over 20 amyloidogenic APOAI mutations have been reported (3-17).

Hereditary apoAI amyloidosis (AApoAI amyloidosis) mainly involves the kidneys $(5-12,17)$, heart (13-15), and liver (16). Clinically, it can particularly resemble systemic immunoglobulin light-chain (AL) amyloidosis, which predominantly involves the kidneys, heart, and liver (18). Thus far, most patients with AApoAI amyloidosis have been reported in Western countries (3,5-16), and it continues to be recognized as a very rare disorder in Asian countries.

We experienced a case of systemic amyloidosis with marked hepatic enlargement in addition to a swelling of the spleen and testis. While this patient was initially thought to have primary AL amyloidosis, a proteomics study showed that the amyloid was composed of a variant form of apoAI.

${ }^{1}$ Department of Medicine (Neurology and Rheumatology), Shinshu University School of Medicine, Japan, ${ }^{2}$ Institute for Biomedical Sciences, Shinshu University, Japan, ${ }^{3}$ Clinical Laboratory Science Division, Shinshu University Graduate School of Medicine (Health Sciences), Japan, ${ }^{4}$ Department of Dementia and Higher Brain Function, Tokyo Metropolitan Institute of Medical Science, Japan, ${ }^{5}$ First Depatment of Medicine, Hamamatsu University School of Medicine, Japan, ${ }^{6}$ Department of Urology, Hamamatsu University Hospital, Japan and ${ }^{7}$ Hepatology Division, Department of Internal Medicine II, Hamamatsu University School of Medicine, Japan

Received: April 19, 2020; Accepted: August 18, 2020; Advance Publication by J-STAGE: September 30, 2020

Correspondence to Dr. Masahide Yazaki, mayazaki@shinshu-u.ac.jp 


\section{Case Report}

A Japanese man with a history of atopic dermatitis and bronchial asthma developed mild liver dysfunction at 30 years old. By 38 years old, he had developed proteinuria with mild renal dysfunction and male infertility. Dyslipidemia and hyperuricemia were also found [serum low-density lipoprotein (LDL)-cholesterol, $221 \mathrm{mg} / \mathrm{dL}$ and uric acid, 8.8 $\mathrm{mg} / \mathrm{dL}]$, and simvastatin (10 mg/day) and febuxostat $(20$ $\mathrm{mg} /$ day) were orally given. In addition, he began to take esomeprazole (10 $\mathrm{mg} /$ day) for gastroesophageal reflux disease. As his liver dysfunction and hepatomegaly gradually progressed [serum alkaline phosphatase (ALP) 797 IU/L and $\gamma$-glutamyl transpeptidase $(\gamma$-GTP) 297 IU/L], he underwent a liver biopsy at Hamamatsu University Hospital at 39 years old, which revealed a massive amyloid deposition, especially in the portal area (Fig. 1A-C). Monoclonal proteins were not detected in serum or urine specimens, and a bone marrow examination demonstrated no proliferation of plasma cells. While the biopsied liver was immunohistochemically stained using antisera against amyloid A protein (AA), transthyretin (TTR), and kappa and lambda immunoglobulin light chains (AL), no samples showed positive results.

From 41 years old, ursodeoxycholic acid (UDCA; 600 $\mathrm{mg} /$ day) was added because serum levels of ALP and $\gamma$-GTP were raised to $985 \mathrm{IU} / \mathrm{L}$ and $384 \mathrm{IU} / \mathrm{L}$. Oral intake of telmisartan $(20 \mathrm{mg} /$ day $)$ was also started for renal protection. In addition, atorvastatin calcium hydrate $(10 \mathrm{mg} /$ day $)$ was substituted for simvastatin due to an insufficient effect.

At 42 years old, he was referred to our hospital for a further examination and treatment, with a tentative diagnosis of systemic AL amyloidosis due to dominant hepatic involvement. He had no family history of amyloidosis, hepatic failure, or renal failure; however, his father had had an enlarged abdomen of unknown etiology and died due to bronchial asthma at 44 years old.

On a physical examination, an abdominal bulge owing to a swollen liver was clearly seen, and a hard-enlarged liver edge was palpable for 8 fingerbreadths (about $12 \mathrm{~cm}$ ) in the right hypochondriac region (Fig. 2A). There were no signs of purpura, jaundice, macroglossia, caput medusae, ascites, or leg edema, nor were there any signs of hepatic encephalopathy or polyneuropathy. The laboratory data are summarized in Table. He had an almost normal liver function, with the exception of elevated serum ALP 1,006 IU/L and $\gamma$-GTP 295 IU/L levels. However, renal dysfunction was observed with high serum levels of urea nitrogen (BUN; $33.2 \mathrm{mg} / \mathrm{dL}$ ) and creatinine $(\mathrm{Cr} ; 2.21 \mathrm{mg} / \mathrm{dL})$. Serum uric acid was also increased $(9.5 \mathrm{mg} / \mathrm{dL})$. Urine protein was positive, and the total amount of urine protein was $2.7 \mathrm{~g} / \mathrm{day}$. His serum levels of apoAI and HDL-cholesterol were mildly decreased (93 and $32 \mathrm{mg} / \mathrm{dL}$, respectively). Severe coagulopathy was not detected. Serum N-terminal prohormone of brain natriuretic peptide (NT-pro BNP) was slightly elevated at 194.0 $\mathrm{pg} / \mathrm{mL}$ (normal <125.0).
There were no findings of amyloid cardiomyopathy on an electrocardiogram and echocardiogram. Upper gastrointestinal endoscopy demonstrated no gastroesophageal varices. Tissue biopsies taken from the duodenal mucosa were positive for amyloid deposition (data not shown). Abdominal computed tomography $(\mathrm{CT})$ revealed a markedly enlarged liver, bilaterally atrophic kidneys with multiple cysts, and swelling of the spleen and bilateral testis (Fig. 2B-D). Chest CT showed no abnormal findings, including no thickening of the bronchial walls (data not shown).

Due to the presence of testicular enlargement and in order to examine his spermatogenic function, a testicular biopsy was also performed at 42 years old. Histopathology demonstrated marked amyloid deposition in degenerated seminiferous tubules and interstitium without spermatogenesis (Fig. 1E, F). The serum testosterone level was less than 5 ng/dL (normal: 131-871), and gonadotropins were elevated (luteinizing hormone: $52.8 \mathrm{mIU} / \mathrm{mL}$, normal: 2.2-8.4 and follicle-stimulating hormone: $123.5 \mathrm{mIU} / \mathrm{mL}$, normal 1.8 12).

\section{Amyloid typing and the APOAl gene analysis}

As the type of amyloidosis remained unknown, a proteomics analysis of liver amyloid using laser-microdissection (LMD) and liquid chromatography-tandem mass spectrometry (LC-MS/MS) was carried out according to previously reported methods (19). In addition to several trypsin-digested peptides derived from the wild-type apoAI, the following two peptides were detected: DSGRDYVSQFK, DYVSQFK (Fig. 3A, B). These peptides corresponded to wild-type apoAI fragments at positions 24-34 and 28-34, except for K34 (wild-type, E34) (Fig. 3B). While apoE was also identified prominently in this study, it is known that apoE abundantly co-exists in all types of amyloid fibrils with serum amyloid P-component (SAP) (20). A further investigation including a genetic study of apoE was therefore not performed.

A direct DNA sequence analysis of the APOAI gene showed that the patient was heterozygous for c.tt172G $>A$ mutation, inducing a substitution of Lys for Glu at position 34 (E34K) (Fig. 3C). To confirm this finding, tissue specimens from the patient's liver, testis, and gastrointestinal mucosa were immunohistochemically stained using goat antihuman apoAI antiserum (ab7613; Abcam, Cambridge, UK), and all specimens showed clearly positive reactions (Fig. 1D, G). A definite diagnosis of AApoAI amyloidosis was thus made at 42 years old.

This study was performed following the tenants of the Declaration of Helsinki. The DNA analysis was conducted after obtaining approval from the IRB of Shinshu University, and written informed consent was obtained from the patient.

\section{Clinical follow-up after a diagnosis of AApoAl amy- loidosis}

To reduce the rate of hepatorenal disease progression and improve his general condition as much as possible, conven- 

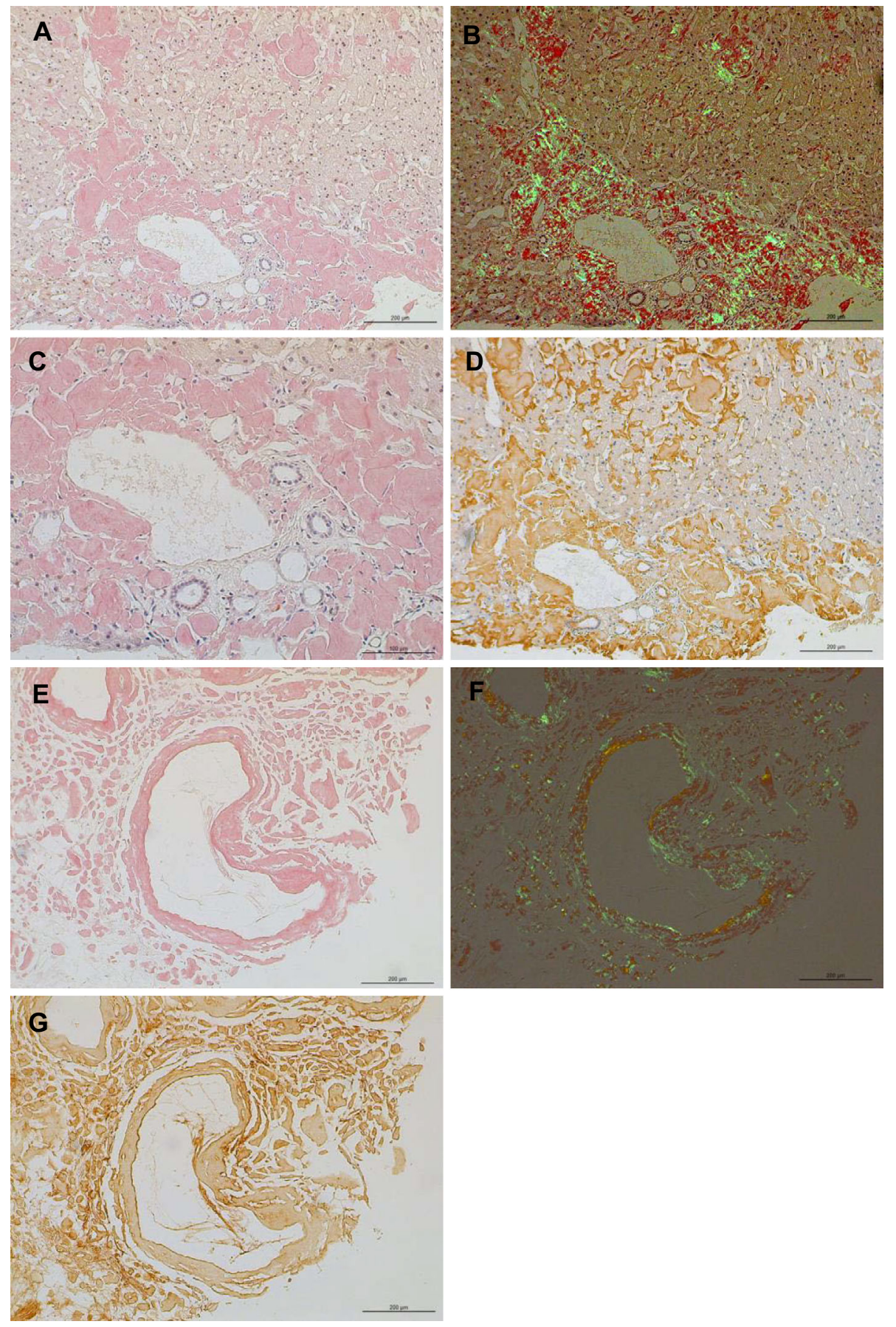

Figure 1. Histopathological findings of biopsied liver (A-D) and testis (E-G) specimens. Congo red staining of the liver biopsy specimen (A, B: polarized view, C) showed massive amyloid deposition, especially in the portal area. In addition, nodular and pericellular amyloid deposits were seen in the lobules. The amyloid deposits immunohistochemically had a positive reaction with anti-human apoAI antibody (D). Testis biopsy specimens showed massive amyloid deposition in the seminiferous tubules and interstitium, and sperm formation was not seen (E, F: polarized view). The amyloid deposits were also positive for anti-human apoAI antibody (G). Bars=200 $\mu \mathrm{m}(\mathrm{A}, \mathrm{B}, \mathrm{D}, \mathrm{E}-\mathrm{G}), 100 \mu \mathrm{m}(\mathrm{C})$. apoAI: apolipoprotein A-I

tional symptomatic treatments with angiotensin receptor blocker, anemia treatment with iron supplement and erythropoietin formulation, and electrolyte level management therapies were performed at outpatient clinics of the nephrology and hepatology divisions at Hamamatsu University Hospital. In addition, a regular checkup and evaluation of his systemic amyloid involvement was performed at Shinshu University. The oral intake of UDCA was stopped at 43 years old because it was thought to have no obvious therapeutic effect on his liver dysfunction (ALP 1,215 IU/L; $\gamma$-GTP 339 IU/ L).

Despite those conventional treatments, however, his liver 
Table. Laboratory Data at 42 Years Old.

\begin{tabular}{|c|c|c|c|c|c|}
\hline White blood cell & $8,880(2,970-9,130)$ & $/ \mu \mathrm{L}$ & Glucose & $93(75-110)$ & $\mathrm{mg} / \mathrm{dL}$ \\
\hline Red blood cell & $4.41(4.14-5.63)$ & $106 / \mu \mathrm{L}$ & Hemoglobin A1c & $5.7(4.6-6.2)$ & $\%$ \\
\hline Hemoglobin & $11(12.9-17.4)$ & $\mathrm{g} / \mathrm{dL}$ & Ammonia & $26(<70)$ & $\mu \mathrm{g} / \mathrm{dL}$ \\
\hline Hematocrit & $33.4(38.6-50.9)$ & $\%$ & & & \\
\hline \multirow[t]{2}{*}{ Platelet } & $14.7(14.3-33.3)$ & $10^{4} / \mu \mathrm{L}$ & $\mathrm{Na}$ & $141(136-145)$ & $\mathrm{mEq} / \mathrm{L}$ \\
\hline & & & K & $4.5(3.4-4.5)$ & $\mathrm{mEq} / \mathrm{L}$ \\
\hline Total protein & $8.3(6.5-8.0)$ & $\mathrm{g} / \mathrm{dL}$ & $\operatorname{IgG}$ & $1819(870-1,700)$ & $\mathrm{mg} / \mathrm{dL}$ \\
\hline Albumin & $4.3(4.0-5.0)$ & $\mathrm{g} / \mathrm{dL}$ & $\operatorname{IgA}$ & $282(110-410)$ & $\mathrm{mg} / \mathrm{dL}$ \\
\hline Blood urea nitrogen & $33.2(8-21)$ & $\mathrm{mg} / \mathrm{dL}$ & $\operatorname{IgM}$ & $200(35-220)$ & $\mathrm{mg} / \mathrm{dL}$ \\
\hline Creatinine & $2.21(0.63-1.05)$ & $\mathrm{mg} / \mathrm{dL}$ & $\mathrm{Ca}$ & $9.5(8.7-10.3)$ & $\mathrm{mg} / \mathrm{dL}$ \\
\hline Uric acid & $9.5(3.7-7.0)$ & $\mathrm{mg} / \mathrm{dL}$ & & & \\
\hline Total-bilirunbin & $0.41(0.3-1.4)$ & $\mathrm{mg} / \mathrm{dL}$ & NTproBNP & $194(<125)$ & $\mathrm{pg} / \mathrm{dL}$ \\
\hline ALP & $1,006(115-330$ & IU/L & TroponinT & $0.008(<0.09)$ & $\mathrm{ng} / \mathrm{mL}$ \\
\hline$\gamma$-GTP & $295(13-70)$ & IU/L & & & \\
\hline AST & $29(11-28)$ & $\mathrm{IU} / \mathrm{L}$ & PT\% & $71.1(70-130)$ & $\%$ \\
\hline ALT & $29(9-36)$ & IU/L & APTT & $24.6(23-38)$ & $\mathrm{sec}$ \\
\hline LDH & $133(120-220)$ & $\mathrm{IU} / \mathrm{L}$ & Fibrinogen & $463(180-350)$ & $\mathrm{mg} / \mathrm{dL}$ \\
\hline $\mathrm{CK}$ & $37(43-272)$ & $\mathrm{IU} / \mathrm{L}$ & D-dimer & $1.5(<1.0)$ & $\mu \mathrm{g} / \mathrm{mL}$ \\
\hline LDL-cholesterol & $139(<139)$ & $\mathrm{mg} / \mathrm{dL}$ & & & \\
\hline HDL-cholesterol & $32(>40)$ & $\mathrm{mg} / \mathrm{dL}$ & $24 \mathrm{hrCCr}$ & $29.6(62-108)$ & $\mathrm{mL} / \mathrm{min}$ \\
\hline Triglyceride & $321(30-149)$ & $\mathrm{mg} / \mathrm{dL}$ & & & \\
\hline ApoAI & $93(122-161)$ & $\mathrm{mg} / \mathrm{dL}$ & Urine sugar & $(-)(-)$ & \\
\hline ApoAII & $32.2(25-35)$ & $\mathrm{mg} / \mathrm{dL}$ & Urine occult blood & $(-)(-)$ & \\
\hline ApoB & $0.09(<0.1)$ & $\mathrm{mg} / \mathrm{dL}$ & Urine protein & $(+++)(-)$ & \\
\hline ApoCII & $4.3(1.6-4.2)$ & $\mathrm{mg} / \mathrm{dL}$ & Total urine protein & 2.7 & g/day \\
\hline ApoCIII & $13.2(5.5-9.5)$ & $\mathrm{mg} / \mathrm{dL}$ & & & \\
\hline ApoE & $5.3(2.7-4.5)$ & $\mathrm{mg} / \mathrm{dL}$ & & & \\
\hline
\end{tabular}

Parentheses denote normal values.

ALP: alkaline phosphatase, $\gamma$-GTP: $\gamma$-glutamyl transpeptidase, AST: aspartate aminotransferase, ALT: alanine aminotransferase, LDH: lactate dehydrogenase, CK: creatine kinase, LDL-cholesterol: low density lipoprotein-cholesterol, HDL-cholesterol: high density lipoprotein-cholesterol, ApoAI: apolipoprotein A-I, ApoAII: apolipoprotein A-II, ApoB: apolipoprotein B, ApoCII: apolipoprotein C-II, ApoCIII: apolipoprotein C-III, ApoE: apolipoprotein E, NTproBNP: N-terminal prohormone of brain natriuretic peptide, PT\%: prothrombin time activity, APTT: activated partial thromboplastin time, 24hrCcr: 24-hour creatinine clearance

and renal function gradually deteriorated over two years. At 44 years old, serum ALP and $\gamma$-GTP were increased to 1,403 and $391 \mathrm{IU} / \mathrm{L}$, respectively. Serum transaminases were mildly increased (aspartate aminotransferase, 53 IU/L; alanine aminotransferase, 44 IU/L). At 45 years old, the serum albumin level and prothrombin time activity (PT\%) were decreased to $3.1 \mathrm{~g} / \mathrm{dL}$ and $57.7 \%$, respectively, and signs of portal hypertension, such as ascites and caput medusae, became apparent. Since the serum levels of BUN and $\mathrm{Cr}$ were increased to 101.3 and $5.51 \mathrm{mg} / \mathrm{dL}$, respectively, hemodialysis was initiated. As he was thought to need liver transplantation or combined hepatorenal transplantation, he was referred to another university hospital to have his eligibility for transplantation evaluated.

\section{Discussion}

Since the first amyloidogenic apoAI variant (G26R) was identified by Nichols et al. (8), over 20 amyloidogenic APOA1 mutations have been reported (3-17). Most of the amyloidogenic mutations are reported in two hot-spot re- gions: among the 50-93 or 170-178 amino acid residues (5).

The E34K mutation detected in our patient was located outside of these hot-spot regions, and only two cases with the same mutation have been reported $(15,21)$. The first case described with this variant was a 29-year-old woman who suffered from amyloid nephropathy (15), and the second case was a 26-year-old man who had infertility due to testicular amyloid and amyloid nephropathy (21). Neither of them had apparent clinical amyloid hepatopathy, as was seen in our patient, but the first case was suspected of having amyloid deposits in the liver and spleen by radiolabeled SAP scintigraphy (15). Thus, the E34K variant may be apt to involve the kidney, testis, and liver. Regarding the mutation-phenotype correlation, Eriksson et al. reported that patients with mutations in codons 1-75 (amino terminal) were likely to develop hepatic and renal amyloidosis, while carriers of mutations in residues 173-178 (carboxyl terminal) mainly develop cardiac, laryngeal, and cutaneous amyloidosis (5). This is consistent with our case and the two reported cases with an E34K mutation $(15,21)$.

Various forms of hereditary systemic amyloidosis have 


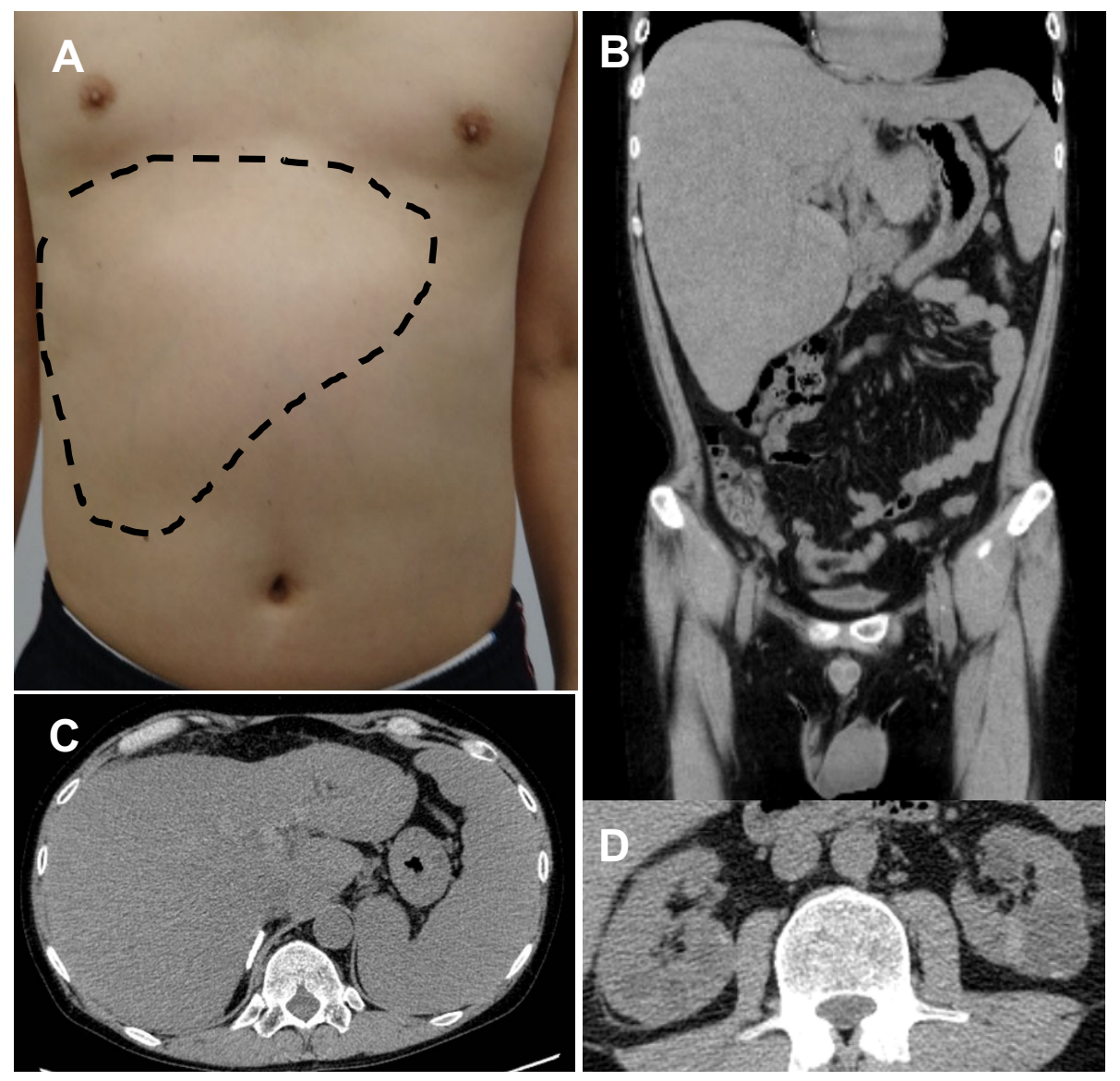

Figure 2. A picture of the patient's abdomen (A) and abdominal CT scan images (B-D). His markedly enlarged liver was palpable, as indicated by the dotted line (A). Coronal section CT showed a markedly enlarged liver and an enlarged left testis (B). Axial section CT showed severe hepatosplenomegaly (C) and bilaterally atrophic kidneys with some cysts (D).

been reported globally (1), and in Japan, hereditary neuropathic amyloidosis is common [hereditary ATTR amyloidosis (TTR-related familial amyloid polyneuropathy (FAP)) and gelsolin-related amyloidosis (AGel amyloidosis)]. Until a patient with fibrinogen-related amyloidosis (AFib amyloidosis) was reported in 2015 (19), no case of hereditary nonneuropathic systemic amyloidosis had been reported in Japan. As for AApoAI amyloidosis, only one patient with two apoAI variants (L202R and K262N) has recently been described (17). A 63-year-old Japanese woman underwent renal transplantation due to amyloid nephropathy (17). The clinical features of AApoAI amyloidosis are heterogeneous, and many systemic organs are involved, including the skin, larynx, and testis. However, the most commonly affected sites are the kidney, liver, and heart (3-17). These organs can be also involved in patients with AL amyloidosis $(18,22)$ or AA amyloidosis, usually induced by inflammatory disorders. As for hepatic amyloidosis in Japan, the vast majority are ascribed to AL or AA amyloidosis (23), and in particular, hepatomegaly is often observed in $\mathrm{AL}$ amyloidosis patients (22). Therefore, hepatic amyloidosis patients without clear family histories can easily be misdiagnosed with systemic AL amyloidosis or AA amyloidosis due to its clinical similarity, as was the case with our patient.
However, the progression rate of hepatic involvement in AApoAI amyloidosis may be slower than that in AL amyloidosis. In our patient, the liver function at the diagnosis of AApoAI amyloidosis (42 years old, Table) was wellpreserved even 3 years after massive amyloid deposits had initially been detected at 39 years old. A previous study also reported the characterization of hepatic AApoAI amyloidosis, with patients remaining stable and asymptomatic for many years until portal hypertension and liver failure later develop (24). However, in some AL amyloidosis patients with hepatic involvement, the liver function rapidly deteriorates, and patients require immediate treatment intervention, including liver transplantation $(25,26)$. Therefore, a slow disease progression in hepatic amyloidosis patients without serum or urine monoclonal protein may be an important characteristic suggestive of AApoAI amyloidosis. In addition, as symptomatic testicular amyloidosis is rarely seen in AL and AA amyloidosis $(22,27)$, infertility or testicular swelling associated with amyloidosis may also be a diagnostic clue for AApoAI amyloidosis.

Finally, even in Japan, patients with hereditary amyloidosis aside from hereditary ATTR and AGel amyloidosis certainly exist. However, most of them may have been misdiagnosed with other types of systemic amyloidosis. Recently, 
A

\begin{tabular}{|l|l|}
\hline Detected protein by LC-MS & emPAI \\
\hline apolipoproteinA-I & 4.26 \\
\hline Serum amyloid P-component & 1.28 \\
\hline Apolipoprotein E & 4.29 \\
\hline Vitronectin & 0.65 \\
\hline Clusterin & 0.68 \\
\hline
\end{tabular}

C

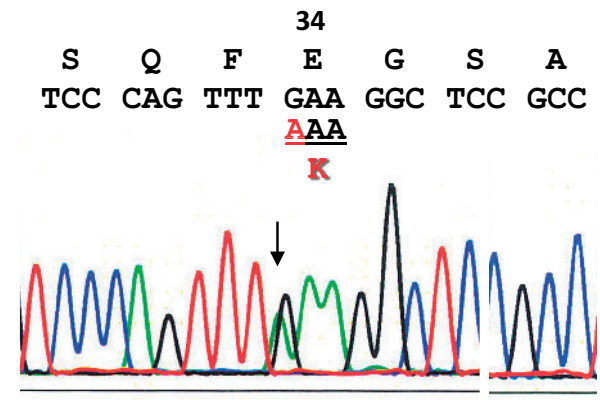

B

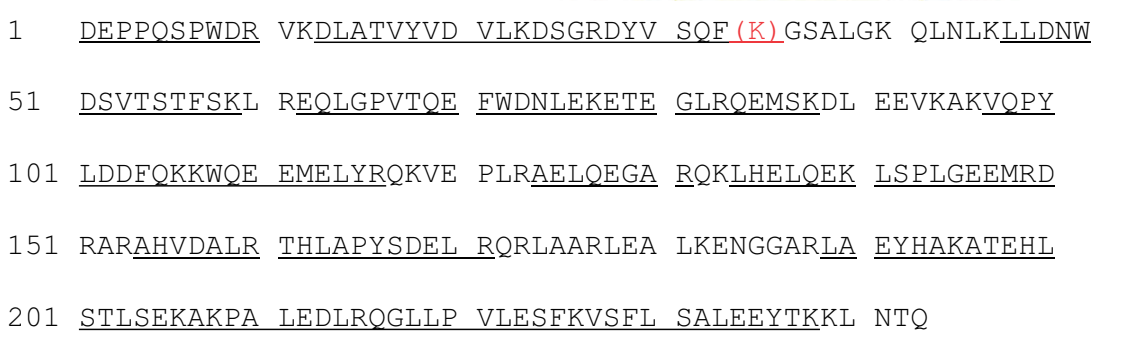

Figure 3. Results of the proteomics analysis (A, B) and APOAI gene analysis (C). A: LC-MS/MSbased proteomic analysis shows the presence of abundant apoAI. The emPAI is the exponentially modified protein abundance index, which is used as an index for estimating relative protein quantification in mass spectrometry-based proteomic analyses (31). B: Amino acid sequence of apoAI with a substitution of $\mathrm{K}$ for $\mathrm{E}$ at position 34 (as shown in red). The peptides detected by LC-MS/MS are indicated by underlining. Several tryptic peptides derived from apoAI were detected. The amino acid at position 34 was only variant $\mathrm{K}$. C: A DNA sequence analysis of the APOAI gene exon 3 demonstrated a heterozygous c.172G >A (E34K) mutation. No other mutations were detected. LC-MS/MS: liquid chromatography-tandem mass spectrometry, apoAI: apolipoprotein A-I

several effective therapies have been established, especially for AL amyloidosis or AA amyloidosis (27-29). In AApoAI amyloidosis, organ transplantation, including that of the kidney, liver, or heart, has been performed as a promising therapy (30). Thus, it is very important to distinguish AApoAI amyloidosis from AL amyloidosis because the strategies used to treat these conditions are completely different. A proteomic analysis using LMD-LC-MS/MS was quite useful for correctly diagnosing the present patient.

The authors state that they have no Conflict of Interest (COI).

\section{Financial Support}

This study was supported by a grant from the Amyloidosis Research Committee, Intractable Disease Division of the Japanese Ministry of Health and Welfare, and Ministry of Education, Culture, Sports, Science and Technology (KAKENHI: 17K 08739, MY).

Tsuneaki Yoshinaga and Nagaaki Katoh contributed equally to this work.

\section{References}

1. Benson MD, Buxbaum JN, Eisenberg DS, et al. Amyloid nomenclature 2018: recommendations by the International Society of Amyloidosis (ISA) nomenclature committee. Amyloid 25: 215-
219, 2018.

2. Obici L, Franceschini G, Calabresi L, et al. Structure, function and amyloidogenic propensity of apolipoprotein A-I. Amyloid 13: 191205, 2006.

3. Tougaard BG, Pedersen KV, Krag SR, et al. A case report of hereditary apolipoprotein A-I amyloidosis associated with a novel APOA1 mutation and variable phenotype. Eur J Med Genet 59: 474-477, 2016.

4. Lu C, Zuo K, Lu Y, et al. Apolipoprotein A-1-related amyloidosis 2 case reports and review of the literature. Medicine 39: e8148, 2017.

5. Eriksson M, Schönland S, Yumlu S, et al. Hereditary apolipoprotein AI-associated amyloidosis in surgical pathology specimens: identification of three novel mutations in the APOA1 gene. J Mol Diagn 11: 257-262, 2009.

6. Traynor CA, Tighe D, O'Brien FJ, et al. Clinical and pathologic characteristics of hereditary apolipoprotein A-I amyloidosis in Ireland. Nephrology 18: 549-554, 2013.

7. Van Allen MW, Frohlich JA, Davis JR. Inherited predisposition to generalized amyloidosis. Clinical and pathological study of a family with neuropathy, nephropathy, and peptic ulcer. Neurology 19: 10-25, 1969.

8. Nichols WC, Gregg RE, Brewer HB Jr, Benson MD. A mutation in apolipoprotein A-I in the Iowa type of familial amyloidotic polyneuropathy. Genomics 8: 318-323, 1990.

9. Booth DR, Tan SY, Booth SE, et al. A new apolipoprotein Al variant, Trp50Arg, causes hereditary amyloidosis. QJM 88: 695-702, 1995.

10. Soutar AK, Hawkins PN, Vigushin DM, et al. Apolipoprotein AI mutation Arg-60 causes autosomal dominant amyloidosis. Proc Natl Acad Sci U S A 89: 7389-7393, 1992.

11. Murphy CL1, Wang S, Weaver K, et al. Renal apolipoprotein A-I 
amyloidosis associated with a novel mutant Leu64Pro. Am J Kidney Dis 44: 1103-1109, 2004.

12. Persey MR1, Booth DR, Booth SE, et al. Hereditary nephropathic systemic amyloidosis caused by a novel variant apolipoprotein A-I. Kidney Int 53: 276-281, 1998.

13. Vonberg FW, Gilbertson JA, Rowczenio D, et al. Amyloid cardiomyopathy associated with a novel apolipoprotein A-I Q172P variant. Amyloid 22: 252-253, 2015.

14. Hamidi Asl L, Liepnieks JJ, Hamidi Asl K, et al. Hereditary amyloid cardiomyopathy caused by a variant apolipoprotein A1. Am J Pathol 154: 221-227, 1999.

15. Rowczenio D, Dogan A, Theis JD, et al. Amyloidogenicity and clinical phenotype associated with five novel mutations in apolipoprotein A-I. Am J Pathol 179: 1978-1987, 2011.

16. Caballería J1, Bruguera M, Solé M, et al. Hepatic familial amyloidosis caused by a new mutation in the apolipoprotein AI gene: clinical and pathological features. Am J Gastroenterol 96: 18721876, 2001.

17. Horike K, Takeda A, Tsujita M, et al. Two novel ApoA1 gene mutations in a Japanese renal transplant recipient with recurrent apolipoprotein A-I related amyloidosis. Nephrology 3 (Suppl): 17-21, 2018.

18. Matsuda M, Katoh N, Ikeda S. Clinical manifestations at diagnosis in Japanese patients with systemic AL amyloidosis: a retrospective study of 202 cases with a special attention to uncommon symptoms. Intern Med 53: 403-412, 2014.

19. Yazaki M, Yoshinaga T, Sekijima Y, et al. The first pure form of Ostertag-type amyloidosis in Japan: a sporadic case of hereditary fibrinogen A $\alpha$-chain amyloidosis associated with a novel frameshift variant. Amyloid 22: 142-144, 2015.

20. Sethi S, Vrana JA, Theis JD, et al. Laser microdissection and mass spectrometry-based proteomics aids the diagnosis and typing of renal amyloidosis. Kidney Int 82: 226-234, 2012.

21. Andeen NK, Lam DY, de Boer IH, et al. Renal ApoA-1 amyloidosis with Glu34Lys mutation and intra-amyloid lipid accumulation. J Am Soc Nephrol 25: 2703-2705, 2014.

22. Shimazaki C, Hata H, Iida S, et al. Nationwide survey of 741 patients with systemic amyloid light-chain amyloidosis in Japan. In- tern Med 57: 181-187, 2018.

23. Iwata T, Hoshii Y, Kawano H, et al. Hepatic amyloidosis in Japan: histological and morphometric analysis based on amyloid proteins. Hum Pathol 26: 1148-1153, 1995.

24. Caballería J, Bruguera M, Solé M, et al. Hepatic familial amyloidosis caused by a new mutation in the apolipoprotein AI gene: clinical and pathological features. Am J Gastroenterol 96: 18721876, 2001.

25. Nakano R, Ohira M, Ide K, et al. Treatment of hepatic amyloid light-chain amyloidosis with bortezomib and dexamethasone in a liver transplant patient. Hepatol Res 45: 150-155, 2015.

26. Ueno A, Katoh N, Aramaki O, et al. Liver transplantation is a potential treatment option for systemic light chain amyloidosis patients with dominant hepatic involvement: a case report and analytical review of the literature. Intern Med 55: 1585-1590, 2016.

27. Okuda Y, Yamada T, Ueda M, Ando Y. First nationwide survey of 199 patients with amyloid A amyloidosis in Japan. Intern Med 57: 3351-3355, 2018.

28. Katoh N, Matsuda M, Tsuchiya-Suzuki A, Ikeda S. Regression of gastroduodenal amyloid deposition in systemic AL amyloidosis after intensive chemotherapies. Br J Haematol 153: 535-538, 2011.

29. Katoh N, Matsushima A, Kurozumi M, Matsuda M, Ikeda S. Marked and rapid regression of hepatic amyloid deposition in a patient with systemic light chain (AL) amyloidosis after high-dose melphalan therapy with stem cell transplantation. Intern Med 53: 1991-1995, 2014.

30. Gillmore JD, Stangou AJ, Lachmann HJ, et al. Organ transplantation in hereditary apolipoprotein AI amyloidosis. Am J Transplant 6: $2342-2347,2006$.

31. Ishihama $Y$, Oda $Y$, Tabata $T$, et al. Exponentially modified protein abundance index (emPAI) for estimation of absolute protein amount in proteomics by the number of sequenced peptides per protein. Mol Cell Proteomics 4: 1265-1272, 2005.

The Internal Medicine is an Open Access journal distributed under the Creative Commons Attribution-NonCommercial-NoDerivatives 4.0 International License. To view the details of this license, please visit (https://creativecommons.org/licenses/ by-nc-nd/4.0/).

(C) 2021 The Japanese Society of Internal Medicine

Intern Med 60: 575-581, 2021 